\title{
LA PREVENCIÓN DE LA RADICALIZACIÓN EN LA ESTRATEGIA CONTRA EL TERRORISMO DE LA UNIÓN EUROPEA. ENTRE SOFT LAW E IMPULSO DE MEDIDAS DE APOYO
}

\author{
Lucas J. RuIz DÍAZ*
}

SUMARIO: 1. INTRODUCCIÓN.-2. LA PREVENCIÓN DE LA RADICALIZACIÓN EN EL MARCO DE LAS MEDIDAS DE LA UNIÓN EUROPEA CONTRA EL TERRORISMO.-2.1. Desarrollo y consolidación de la estrategia europea de prevención de la radicalización terrorista.-2.2. Principales elementos.-2.2.1. Las acciones preventivas: investigación de los procesos de radicalización e intervención sobre el entorno socioeconómico y educativo.-2.2.2. Las acciones represivas contra la radicalización: intervención desde el sector de la seguridad.-2.2.3. Las acciones de desvinculación, rehabilitación y reintegración.-3. LA PREVENCIÓN DE LA RADICALIZACIÓN TERRORISTA EN LA ESTRATEGIA EXTERIOR DE LA UNIÓN EUROPEA.-4. CONCLUSIONES.

\section{INTRODUCCIÓN}

1. La lucha contra el terrorismo no es un cometido nuevo en la historia de la integración europea ${ }^{1}$. Progresivamente, si bien con mayor celeridad tras los atentados del 11 de septiembre de 2001 en los Estados Unidos, la Unión Europea (UE) ha adoptado una serie de instrumentos que abordan la prevención y represión del terrorismo en sus diversas manifestaciones, impulsando la respuesta internacional ante un fenómeno global que ha mostrado una evolución preocupante y de nefastas consecuencias para la seguridad de la ciudadanía y de los Estados. Dentro de este marco general, la UE ha prestado especial atención durante la última década a las medidas de prevención

* Doctor en Derecho Internacional Público y Relaciones Internacionales, Universidad de Granada, (lucasruiz@ugr.es). Investigador visitante en el Institute for European Studies de la Vrije Universiteit Brussel (IES, VUB). Todas las páginas web a las que se hace referencia fueron consultadas por última vez el 30 de abril de 2017.

1 Coolsaet, R. (ed.), Jihadi Terrorism and the Radicalisation Challenge. European and American Experiences, 2. ${ }^{a}$ ed., Nueva York, Routledge, 2012; y Hoffman, B. y ReINARES, F. (eds.), The Evolution of the Global Terrorist Threat: From 9/11 to Osama bin Laden's Death, Nueva York, Columbia University Press, 2014. 
del terrorismo y, en particular, de la radicalización terrorista, aportando una estrategia específica e instrumentos de apoyo que completan los esfuerzos de las autoridades nacionales en este ámbito de la seguridad, reducto de la soberanía de los Estados miembros (EEMM). Sin embargo, en opinión de Fernando Reinares, las medidas europeas de prevención de la radicalización yihadista han fracasado ${ }^{2}$. Sin llegar a ser tan categóricos en esta crítica, es indiscutible que estas pretensiones se han mostrado insuficientes, dadas las lagunas identificadas por los servicios policiales y de inteligencia de los EEMM en la contención del reclutamiento por parte de grupos terroristas y la prevención del paso hacia posturas radicales de ciudadanos europeos o, en último término, de la comisión de actividades terroristas, como han evidenciado los sucesivos atentados cometidos en el último año en Europa.

2. Estos ataques terroristas en territorio europeo han puesto de relieve, asimismo, la simplicidad con la que algunos discursos oficiales han abordado la complejidad del fenómeno. Así, seguramente influidas por los acontecimientos del actual lustro y la presión mediática, algunas instancias internacionales y europeas han centrado últimamente su respuesta en materia de prevención del terrorismo en la figura de los combatientes extranje$\operatorname{ros}^{3}$-llegando incluso a asimilarlos, erróneamente, a las redes terroristas internacionales ${ }^{4}$ - , con el fin de evitar que retornen y perpetren actos terroristas en sus respectivos países de origen o se conviertan en "catalizadores del terrorismo» ${ }^{5}$. En realidad, la prevención del extremismo violento y de la radicalización que conduce al terrorismo precisa de una intervención particular más amplia y multidisciplinar, independiente de la lucha contra

2 ReINARES, F., «Prevenir la radicalización yihadista: un fracaso europeo», disponible en: http:// www.blog.rielcano.org/prevenir-la-radicalizacion-yihadista-un-fracaso-europeo/.

3 Sirvan de ejemplo, en el caso de la UE, las Resoluciones del Parlamento Europeo, de 11 de febrero de 2015, sobre las medidas de lucha contra el terrorismo [P8_TA(2015)0032], y de 25 de noviembre de 2015, sobre la prevención de la radicalización y el reclutamiento de ciudadanos europeos por organizaciones terroristas [P8_TA(2015)0410]. En esta misma línea, véase la Directiva 2017/541, del Parlamento Europeo y del Consejo, relativa a la lucha contra el terrorismo ( $D O$ L núm. 88 , de 31 de marzo de 2017). A nivel internacional, el paso ha estado marcado por el discurso del Consejo de Seguridad de las Naciones Unidas, igualmente centrado en estos últimos años en la prevención de la radicalización y el extremismo violento ligados a la cuestión de los combatientes extranjeros, como prueba la Resolución 2178 (2014), de 24 de noviembre. Para un análisis de esta última, véanse: GARRIDO MuÑoz, A., «Un nuevo cortocircuito legislativo en Naciones Unidas: la Resolución 2178 (2014) del Consejo de Seguridad de Naciones Unidas relativa a los combatientes terroristas extranjeros", Revista Española de Derecho Internacional, vol. 67, 2015, núm. 1, pp. 303-307; y MARRERO RocHA, I., «Los combatientes "terroristas” extranjeros de la Unión Europea a la luz de la Resolución 2178 (2014) del Consejo de Seguridad de las Naciones Unidas», Revista de Derecho Comunitario Europeo, 2016, núm. 54, pp. 555-594.

4 «Desde la perspectiva del Derecho internacional [...] es al mismo tiempo simplista y jurídicamente confuso imponer tal asociación, porque diferentes ramas del Derecho internacional rigen el conflicto armado y la prevención y supresión del terrorismo»: véase «Foreign Fighters under International Law», Geneva Academy of International Humanitarian Law and Human Rights Briefing, octubre, 2014, núm. 7, p. 3 (traducción propia), disponible en: https://www.geneva-academy.ch.

5 «Comunicación de la Comisión al Parlamento Europeo, al Consejo, al Comité Económico y Social Europeo y al Comité de las Regiones. Prevenir la radicalización hacia el terrorismo y el extremismo violento: una respuesta más firme de la UE», COM (2013) 941 final, Bruselas, de 15 de enero de 2014, p. 2. 
los combatientes extranjeros para ser efectiva, como demuestran las últimas investigaciones policiales contra el terrorismo ${ }^{6}$. No obstante, dicha intervención suscita numerosas controversias incluso en nuestros días, empezando por el alcance del propio concepto radicalización, excesivamente ambiguo para parte de la doctrina y con un recorrido dispar a nivel internacional ${ }^{7}$ que sigue siendo actualmente objeto de debate en el seno de la $\mathrm{UE}^{8}$.

3. Conscientes de esta incertidumbre, los actores del Espacio de Libertad, Seguridad y Justicia (ELSJ) ${ }^{9}$ han ido progresivamente perfilando y consolidando el término radicalización en el marco de las medidas antiterroristas de la UE. En una primera aproximación, simple pero operativa, la Comisión Europea definió la «radicalización violenta» como un «fenómeno en virtud del cual las personas se adhieren a opiniones, puntos de vista e ideas que pueden conducirles a cometer actos terroristas ${ }^{10}$. De esta forma, el término ha ido cobrando protagonismo en el discurso y agenda comunitarios para, como afirma Rik Coolsaet, convertirse, en 2005, en el «Santo Grial de la lucha antiterrorista europea ([...], contribuyendo) significativamente al cambio de enfoque, del contexto al individuo» ${ }^{11}$; es decir, dejando a un lado concepciones ligadas al entorno socioeconómico o causas subyacentes para ceñirse a

6 «Los Estados e instituciones internacionales han decidido equiparar el combatiente islamista radical europeo con el terrorista y han adoptado reformas legales y administrativas destinadas a prevenir una diáspora europea a esos conflictos. (... Sin embargo, la) experiencia demuestra que son los «combatientes domésticos o internos» sin experiencia como combatientes fuera de sus países quienes han llevado a cabo hasta el momento el mayor número de atentados en los países occidentales». MARRERo Rосна, I., "Foreign Fighters and Jihadists: challenges for international and European security», Revue Paix et Sécurité Internationales, 2015, núm. 3, pp. 107-108 (traducción propia).

7 En este sentido, Estados Unidos y la Organización de las Naciones Unidas (ONU) prefieren utilizar el término extremismo violento. Para un análisis de la evolución de ambos términos en el discurso de las instituciones y la doctrina, así como en perspectiva comparada, véanse: ANTón MELlóN, J., Islamismo yihadista: radicalización y contrarradicalización, Valencia, Tirant lo Blanch, 2015; CoOLSAET, R., "All Radicalisation is Local". The genesis and drawbacks of an elusive concept», Egmont Papers, Bruselas, Royal Institute for International Relations, 2016, núm. 84, en: http://www.egmontinstitute.be/ publication/; JoRdÁn ENAMORADO, J., «Políticas de prevención de la radicalización violenta en Europa: elementos de interés para España», Revista Electrónica de Ciencia Penal y Criminología, 2009, núm. 1105, en: http://criminet.ugr.es/recpc/11/recpc11-05.pdf; REINARES, F. et al., Radicalisation Processes Leading to Acts of Terrorism. A concise Report prepared by the European Commission's Expert Group on Violent Radicalisation, de 15 de mayo de 2008; SchmID, A. P., «Radicalisation, De-Radicalisation, CounterRadicalisation: A Conceptual Discussion and Literature Review», ICCT Research Paper, International Centre for Counter-Terrorism (ICCT), 2013, núm. 2, en: https://www.icct.nl/.

8 Europol ha propuesto recientemente eliminar el concepto radicalización para hablar de «tendencias sociales de extremismo violento»: véase "Changes in modus operandi of Islamic State terrorist attacks», 2016, p. 6. Por su parte, en junio de 2016, el Comité Europeo de las Regiones instó a la Comisión a llegar a «un acuerdo para elaborar una definición común del fenómeno de la radicalización violenta como punto de partida para adoptar un enfoque más coordinado [...], con la contribución de los entes locales y regionales» (Dictamen CIVEX-VI/010, de 16 de junio de 2016).

9 Entenderemos por «actores» del ELSJ tanto las instituciones con competencia directa en materia de seguridad (Consejo, Comisión y Parlamento Europeo), como las agencias europeas y los órganos preparatorios y grupos de trabajo del Consejo directamente relacionados con estas áreas.

10 «Comunicación de la Comisión al Parlamento Europeo y al Consejo sobre la captación de terroristas: afrontar los factores que contribuyen a la radicalización violenta», COM (2005) 313 final, Bruselas, de 21 de septiembre de 2005, p. 2.

11 Coolsaet, R., op. cit., nota 7, pp. 20 y 27 (traducción propia). 
un término considerado más neutral por los servicios de la Comisión ${ }^{12}$. Como advertiremos, adoptar este término no ha sido óbice para invocar el contexto socioeconómico del individuo (o los «factores subyacentes») en el marco de la intervención comunitaria en otros ámbitos desligados de las medidas de seguridad, en los que la UE posee competencias meramente subsidiarias.

4. Sabedores igualmente de la relación entre la seguridad interior y exterior, desde el comienzo estos actores han impulsado la adopción de medidas antiterroristas por parte de terceros Estados y el refuerzo de la respuesta internacional como complemento a su política de prevención. Así, ya la Estrategia Europea de Seguridad (EES, 2003), que incluía al terrorismo entre las amenazas a la seguridad de la Unión, respaldaba una UE más activa a nivel internacional, en particular en relación a la solución de conflictos enquistados que pueden conducir al terrorismo en determinados individuos, apuntando (tímidamente) por primera vez en un documento oficial a las causas subyacentes o factores que pueden conducir al extremismo violento y la radicalización ${ }^{13}$. En 2016, la Estrategia Global sobre Política Exterior y de Seguridad de la UE vendría a reafirmar este compromiso internacional contra el extremismo violento y la radicalización que conduce al terrorismo, proponiendo «estar a la altura» de los valores sobre los que se fundamenta la Unión como «el mejor antídoto» ${ }^{14}$ para evitar su propagación. Por tanto, tras superar una primera concepción del terrorismo como algo esencialmente externo al orden europeo ${ }^{15}$, la dimensión exterior de la prevención de la radicalización terrorista ha pasado a ser parte esencial de la estrategia europea como refuerzo de las medidas previstas a nivel interno. Esta actuación vendría a completar — desde el ELSJ_ las escasas medidas puestas en marcha contra el terrorismo en el marco de la Política Exterior y de Seguridad Común (PESC) y, en particular, a reforzar la contribución de la Política Común de Seguridad y Defensa (PCSD) al mantenimiento de la seguridad interior ${ }^{16}$.

12 Ibid., p. 13.

13 «La más reciente oleada de terrorismo tiene un alcance mundial y está relacionada con el extremismo religioso violento. Surge de complejas causas, entre las que se encuentran la presión de la modernización, las crisis culturales, sociales y políticas y la alienación de los jóvenes que viven en sociedades extranjeras. Este fenómeno forma también parte de nuestra propia sociedad»: véase CoNSEJO EuRoPEO, «Una Europa segura en un mundo mejor. Estrategia europea de seguridad», de 12 de diciembre de 2003, p. 3.

${ }^{14}$ Una visión común, una actuación conjunta: una Europa más fuerte. Estrategia global para la política exterior y de seguridad de la Unión Europea, refrendada por el Consejo Europeo en su reunión de 15 de diciembre de 2016, p. 16. Sobre las aportaciones de la Estrategia Global al panorama estratégico europeo, véase Liñán Nogueras, D. J., «Un nuevo discurso estratégico para la Política Exterior de la Unión Europea», Revista de Derecho Comunitario Europeo, 2017, núm. 56, pp. 11-24.

15 Apreciable especialmente es el énfasis puesto en el terrorismo internacional tras los ataques del 11 de septiembre, como se refleja en las Conclusiones del Consejo Europeo extraordinario, celebrado el 21 de septiembre, o en los primeros informes de actividad de Europol. Esta conceptualización del terrorismo como un fenómeno externo al orden europeo ha sido defendido prácticamente hasta la adopción de la Estrategia de la UE contra el Terrorismo de 2005 (14469/4/05), en la que ya esta referencia es más sutil, si bien se sigue fijando esencialmente en el terrorismo internacional de $-\mathrm{o}$ inspirado en- Al Qaeda, considerado este «tipo de terrorismo [...] la principal amenaza para la Unión en su conjunto» (p. 7).

16 Estrictamente en el marco de la PESC y de la contribución de la PCSD a la lucha contra el terrorismo, la UE se ha limitado a implementar las medidas impulsadas por el Consejo de Seguridad de las 
5. El presente Estudio analiza las medidas puestas en marcha por la UE en materia de prevención de la radicalización, entendidas como un pilar fundamental en el actual enfoque de la política europea contra el terrorismo. Con este análisis pretendemos contribuir al debate sobre la oportunidad y conveniencia de la perspectiva europea, criticada por ineficaz, entre otros autores, por Fernando Reinares. Para ello, realizaremos un primer examen de las iniciativas e instrumentos adoptados en el seno de la Unión (epígrafe 2), en el que apreciaremos los principales límites del enfoque de la UE. Por un lado, por razones de oportunidad política, este se ha centrado esencialmente en la radicalización al terrorismo de corte yihadista, obviando que estas medidas han de tener un carácter más amplio para abarcar también otros extremismos violentos provenientes de diferentes ideologías y religiones si quiere resultar eficaz y, así, evitar caer en la «victimización» de la narrativa yihadista que pretende contrarrestar ${ }^{17}$. Por otro, no hemos de olvidar que, a excepción de determinados elementos en materia de justicia penal, la intervención comunitaria es meramente subsidiaria según el reparto competencial operado por el Tratado de Lisboa ${ }^{18}$, cuestión que ha condicionado el alcance real - material y formal-de las medidas adoptadas ${ }^{19}$. Especialmente problemática y compleja es la cooperación con terceros Estados y organismos internacionales en materia de prevención de la radicalización (epígrafe 3), cuyo análisis requiere de atención para comprender la estrategia de la UE y sus límites en la práctica. Si bien son numerosos los instrumentos de los que la Unión dispone, estos se encuentran coartados en la mayoría de las ocasiones por las agendas e intereses del país en cuestión y por la propia naturaleza de los instrumentos puestos en marcha para promover la prevención

\footnotetext{
Naciones Unidas, especialmente en cuanto a las sanciones «inteligentes» y, más recientemente, sobre "combatientes extranjeros», y a desplegar misiones y operaciones en el territorio de terceros Estados destinadas a combatir el terrorismo sobre el terreno y a formar a los cuerpos y fuerzas de seguridad locales. Este compromiso de la UE con la prevención y represión del terrorismo y la radicalización desde la perspectiva de la seguridad y la defensa fue reiterado recientemente por el Consejo, en sus Conclusiones de noviembre de 2016 (14149/16, Bruselas, de 14 de noviembre de 2016), si bien no es precisamente el marco más idóneo para este tipo de iniciativas. Sobre estos ámbitos, véanse: KEOHANE, D., "The Absent Friend: EU Foreign Policy and Counter-Terrorism», Journal of Common Market Studies, vol. 46, 2008, núm. 1, pp. 125-146; y RuIz Díaz, L. J., «La contribución de la Política Común de Seguridad y Defensa a la seguridad interior de la Unión Europea», en RoldÁn BARBERo, J., La nueva Política de Seguridad y Defensa de la Unión Europea, Granada, Servicio Editorial de la Universidad de Granada, 2012, pp. 121-141.

17 Schmid, A. P., op. cit., nota 7, pp. 59-60.

18 Véanse el art. 4, Competencias compartidas (ELSJ); el art. 5, Coordinación de políticas nacionales (empleo); y el art. 6, Competencias de apoyo, coordinación y complemento (educación, formación profesional, juventud y cultura) del Tratado de Funcionamiento de la UE (TFUE). Adicionalmente, el art. 72 del TFUE. Versiones consolidadas del Tratado de la UE y del TFUE en DO C núm. 83, de 30 de marzo de 2010, pp. 1-403.

19 «A nivel de la UE, [...] las varias estrategias y programas, mecanismos, redes y plataformas que han sido creadas no son más que para inspirar y animar a los Estados miembros a desarrollar políticas e instrumentos a nivel nacional y local. No hay mecanismos en marcha ni obligaciones de informar para monitorizar el seguimiento e implementación de los objetivos políticos formulados en los documentos estratégicos. En este sentido, es imposible medir la eficacia formal en este ámbito político, por no hablar de la eficacia material». Wensink, W. et al., The European Union's Policies on Counter-Terrorism. Relevance, Coherence and Effectiveness, Estudio solicitado y publicado por el Parlamento Europeo, Bruselas, 2017, p. 63 (traducción propia).
} 
de la radicalización fuera de nuestras fronteras, entre el soft law y el simple voluntarismo político.

\section{LA PREVENCIÓN DE LA RADICALIZACIÓN EN EL MARCO DE LAS MEDIDAS DE LA UNIÓN EUROPEA CONTRA EL TERRORISMO}

6. En los últimos años, la UE y sus EEMM han prestado especial atención a la prevención de la radicalización, «justificada por la necesidad de cegar las fuentes que alimentan las redes terroristas y de privar a estas de una base social de apoyo» ${ }^{20}$. Inducida en un primer momento por las políticas de Países Bajos y Reino Unido, la principal aportación de la Unión va a ser, no obstante, promover el debate interno y proponer una respuesta común al riesgo de la propagación de mensajes radicales y extremistas violentos dentro del planteamiento global en la prevención del terrorismo, dado el carácter subsidiario de sus competencias en este ámbito de la seguridad. Por ello, su labor ha quedado reducida en la práctica a completar y apoyar la actuación de los EEMM, coordinar las políticas nacionales y promover medidas desde el Derecho penal y el ELSJ, pilar represivo de la política antiterrorista donde la UE concentra la mayor parte de su intervención.

\subsection{Desarrollo y consolidación de la estrategia europea de prevención de la radicalización terrorista}

7. Si por algo se ha caracterizado la política antiterrorista de la UE ha sido por su carácter reactivo ${ }^{21}$, por lo que los grandes impulsos del ELSJ en este sentido han derivado de ataques que han ocasionado una fuerte conmoción social e impacto mediático en Europa. Así, días después de los atentados de marzo de 2004 en Madrid, el Consejo adoptó la Declaración sobre la lucha contra el terrorismo, en la que pedía que las medidas previstas en la EES para atajar este fenómeno criminal y otros instrumentos en negociación se impulsaran con carácter urgente, al mismo tiempo que, en este marco general, solicitaba «reflexionar sobre los factores que propician el apoyo al terrorismo y la captación de terroristas» y elaborar una estrategia a largo plazo que abordase «todos los factores que contribuyen al terrorismo» ${ }^{22}$. Con estas referencias, se ponía fin a la ausencia de este y otros ámbitos de la prevención del terrorismo

\footnotetext{
20 JoRdÁn EnAMORADO, J., op. cit., nota 7, p. 25.

21 Son muchos los autores que opinan en este sentido. Véanse, por ejemplo: BuREs, O., «EU Counterterrorism Policy: A Paper Tiger?», Terrorism and Political Violence, vol. 18, 2006, núm. 1, pp. 57-78; Powell, C. y Sorroza, A., «La Unión Europea y la lucha contra el terrorismo global», Política Exterior, enero-febrero, 2009, núm. 127, pp. 127-137; y RENARD, T., «EU Counterterrorism Policies and Institutions After the Lisbon Treaty», Policy Brief, Center on Global Counterterrorism Cooperation, septiembre, 2012, disponible en www.globalct.org; y WENSINK, W. et al., op. cit., nota 19.

22 Consejo de la Unión Europea, «Declaración sobre la lucha contra el terrorismo», 7906/04, Bruselas, de 29 de marzo de 2004, pp. 3 y 10.
} 
en instrumentos anteriores, adoptados en el tumulto legislativo y programático posterior al 11-S y centrados en la represión de los actos terroristas y la lucha contra su financiación, como la Decisión marco contra el terrorismo ${ }^{23}$, la orden europea de detención y entrega ${ }^{24}$ o el Plan de Acción en materia de terrorismo del Consejo Europeo extraordinario de 21 de septiembre de $2001^{25}$ - cuyos objetivos estratégicos serían revisados para incluir otros sectores de actuación-. Este intenso trabajo de las instituciones condujo a la adopción, en noviembre de 2005, de la Estrategia de la UE contra el Terrorismo ${ }^{26}$, basada en los cuatro pilares que sentarían las bases de la política antiterrorista hasta nuestros días: prevenir, proteger, perseguir y responder.

8. Específicamente en materia de prevención, la lucha contra la radicalización que conduce al terrorismo ha adquirido un protagonismo clave en la agenda de los actores del ELSJ, alentados por los actos terroristas en territorio europeo (Madrid, Londres, Copenhague, París y Bruselas). Con la publicación de una Comunicación ${ }^{27}$, la Comisión pondría las primeras piezas de un complejo rompecabezas iniciado en marzo y reafirmado en diciembre de 2004 por el Consejo Europeo ${ }^{28}$, comprendido en el Programa de La Haya ${ }^{29}$ y consumado en la Estrategia de la UE contra la radicalización, finalmente adoptada por el Consejo en noviembre de $2005^{30}$. Esta actuación complementaba el marco general de medidas antiterroristas preventivas anunciado por la Estrategia contra el Terrorismo con una serie de acciones específicas destinadas a apoyar y completar las políticas de los EEMM en sectores de muy diversa índole, desde el fomento de disposiciones en materia de educación, inclusión social e igualdad de oportunidades, hasta la promoción del diálogo intercultural e interreligioso, pasando por el recurso al Derecho penal para tipificar determinadas conductas relacionadas (véase el siguiente epígrafe). Además, afianzaba el uso de este concepto frente a otros términos que habían marcado

${ }^{23}$ Decisión marco 2002/475/JAI, del Consejo, de 13 de junio, sobre la lucha contra el terrorismo (DO L núm. 164, de 22 de junio de 2002, pp. 3-7).

24 Decisión Marco 2002/584/JAI, del Consejo, de 13 de junio, relativa a la orden de detención europea y a los procedimientos de entrega entre Estados miembros ( $D O$ L núm. 190, de 18 de julio de 2002, pp. 1-18).

${ }_{25}$ Centrado, únicamente, en la prevención de la financiación del terrorismo y el embargo preventivo de bienes susceptibles de ser utilizados en la comisión de actos terroristas. CONSEJO EUROPEO, "Conclusiones y Plan de Acción del Consejo Europeo extraordinario de 21 de septiembre de 2001». Adicionalmente, CONSEJO DE LA UNIÓN EuROPEA, «Coordinación de la puesta en práctica del plan de acción para la lucha contra el terrorismo», 12800/1/01 REV 1, Bruselas, de 17 de noviembre de 2001.

26 Consejo de la Unión Europea, «Estrategia de la Unión Europea de Lucha contra el Terrorismo», 14469/4/05 REV 4, Bruselas, de 30 de noviembre de 2005.

27 Comisión de las Comunidades Europeas, COM (2005) 313 final, op. cit., nota 10. Anteriormente, «Comunicación de la Comisión al Consejo y al Parlamento Europeo. Prevención, preparación y respuesta a los ataques terroristas», COM (2004) 698 final, Bruselas, de 20 de octubre de 2014.

28 Consejo de la Unión Europea, «Consejo Europeo de Bruselas 16 y 17 de diciembre de 2004. Conclusiones de la Presidencia», 16238/04, Bruselas, de 17 de diciembre de 2004, en particular su punto 26 .

29 «El Programa de La Haya: Consolidación de la Libertad, la Seguridad y la Justicia en la Unión Europea», DO C núm. 53, de 3 de marzo de 2005.

30 CONSEJo de la UNIÓN EuRoPEA, «Estrategia de la Unión Europea para luchar contra la radicalización y la captación de terroristas», 14781/1/05 REV 1, Bruselas, de 25 de noviembre de 2005. 
el debate europeo y estatal durante años ${ }^{31}$. Esta Estrategia contra la radicalización sería posteriormente revisada en dos ocasiones $\left(2008\right.$ y 2014) ${ }^{32}$, siendo igualmente objeto de atención en otros documentos e instrumentos en los que el terrorismo y la prevención de la radicalización han sido identificados como una prioridad en la integración europea, dentro de un marco de acción más amplio en materia de seguridad, como la Agenda Europea de Seguridad $(2015)^{33}$ y la Estrategia de Seguridad Interior renovada (2015) ${ }^{34}$.

9. Teniendo siempre presente que es una cuestión de competencia directa de las autoridades de los EEMM ${ }^{35}$, la intervención de la UE en materia de prevención de la radicalización prevista por la Estrategia europea y su plan de acción ha estado centrada en tres esferas interconectadas: prevención, represión y desvinculación. Sin embargo, el carácter subsidiario de las medidas comunitarias ha impuesto los principales límites a su alcance formal (o normativo) y, sobre todo, material (o de contenido). El énfasis puesto en la prevención de la radicalización en el nivel programático ha marcado la hoja de ruta para la consolidación del ELSJ contra el terrorismo, pero se ha quedado en un segundo plano en el resto de ámbitos cubiertos por la prevención de la radicalización -en los que la UE posee competencia subsidiaria-, como el educativo y el social, eludiendo abordar otros aspectos del extremismo violento y la radicalización no relacionados con el terrorismo. Por tanto, deseado o no (fruto del reparto competencial), el enfoque preventivo seguido por la UE resulta eminentemente "securitario», afrontando de manera sesgada el fenómeno de la radicalización.

31 En algunos EEMM, con carácter previo e individual, se había optado por el término extremismo violento, si bien no han de ser considerados sinónimos. Sobre las diferencias entre uno y otro término, véase ScHMID, A. P., op. cit., nota 7.

32 En la última década, son varios los debates y revisiones que se han sucedido con el fin de reexaminar la estrategia contra la radicalización terrorista de la UE. Así, por ejemplo, el Consejo y sus órganos preparatorios han debatido en numerosas ocasiones la revisión de la Estrategia de 2005, dando lugar a las actualizaciones de 2008 (15175/08) y 2014 (9956/14). Asimismo, la Comisión y el Parlamento Europeo han participado activamente en el debate institucional, con tres comunicaciones y una Resolución de especial relevancia: véanse «Prevenir la radicalización hacia el terrorismo y el extremismo violento: una respuesta más firme de la UE» [COM (2013) 941 final, de 15 de enero de 2014]; Resolución, de 25 de noviembre de 2015, sobre la prevención de la radicalización y el reclutamiento de ciudadanos europeos por organizaciones terroristas, P8_TA(2015)0410; «Aplicación de la Agenda Europea de Seguridad para luchar contra el terrorismo y allanar el camino hacia una Unión de la Seguridad genuina y efectiva» [COM (2016) 230 final, de 20 de abril de 2016]; y "Apoyo a la prevención de la radicalización que conduce al extremismo violento» [COM (2016) 379 final, de 14 de junio de 2016].

33 «Comunicación de la Comisión al Parlamento Europeo, al Consejo, al Comité Económico y Social Europeo y al Comité de las Regiones. Agenda Europea de Seguridad», COM (2015) 185 final, Estrasburgo, de 28 de abril de 2015, en particular su punto «3.1. Lucha contra el terrorismo y prevención de la radicalización».

34 Consejo de la Unión Europea, «Proyecto de Conclusiones del Consejo sobre la Estrategia renovada de Seguridad Interior de la Unión Europea 2015-2020», 9798/15, Bruselas, de 10 de junio de 2015.

35 «El reto de luchar contra la radicalización y la captación de terroristas es fundamentalmente competencia de los Estados miembros, a nivel nacional, regional y local». CONSEJO DE LA UNIÓN EUROPEA, «Estrategia de la Unión Europea para luchar contra la radicalización y la captación de terroristas», 14781/1/05 REV 1, Bruselas, de 25 de noviembre de 2005, p. 6. Este mensaje sería repetido en las sucesivas revisiones de la Estrategia. 


\subsection{Principales elementos}

10. En su Comunicación de junio de 2016 —en línea con documentos anteriores, como la Agenda Europea de Seguridad y la propia Estrategia contra la radicalización ${ }^{36}$ - la Comisión propuso siete ámbitos específicos en los que la Unión debía orientar su actuación de soporte a las autoridades estatales: i) apoyo a la investigación, la constitución de pruebas, el seguimiento y el establecimiento de redes; ii) lucha contra la propaganda terrorista y el discurso del odio en internet; iii) lucha contra la radicalización en los centros penitenciarios; iv) fomento de la educación inclusiva y los valores comunes de la Unión; v) fomento de una sociedad inclusiva, abierta y resiliente y conexión con los jóvenes; vi) lucha contra la radicalización desde la perspectiva de la seguridad, y vii) dimensión internacional ${ }^{37}$. En el marco de estos ámbitos prioritarios, la Comisión proponía 26 acciones clave concretas que desarrollarían y programarían para los próximos años los principales puntos de la Estrategia contra la radicalización del Consejo, bastante más genérica y difusa en cuanto a las iniciativas a poner en marcha. En rasgos generales, la actuación de la UE en materia de prevención de la radicalización terrorista puede subsumirse en los siguientes pilares: acciones preventivas de apoyo y complemento, represivas y, por último, de «desradicalización» y desvinculación.

\subsubsection{Las acciones preventivas: investigación de los procesos de radicalización e intervención sobre el entorno socioeconómico y educativo}

11. La respuesta de la UE en el terreno preventivo ha estado principalmente encaminada a intervenir en una fase temprana, identificando factores de alarma y de propagación de mensajes radicales, e impedir que las personas en riesgo sean captadas por grupos terroristas. Conscientes de que la prevención de la radicalización comienza por un conocimiento fundado sobre el fenómeno y las causas subyacentes que llevan a los individuos a apoyar visiones extremas y - en último término, aunque no siempre- a la comisión de actos terroristas, la UE ha puesto especial énfasis, en primer lugar, en investigar los factores contextuales y personales que pueden derivar en conductas

36 La Estrategia contra la radicalización del Consejo apuesta por los siguientes diez ámbitos de actuación, coincidentes, grosso modo, con los propuestos por la Comisión: i) Promover la seguridad, la justicia y la igualdad de oportunidades para todos; ii) Garantizar que la voz de la opinión mayoritaria prevalezca sobre el extremismo; iii) Mejorar las comunicaciones de los gobiernos; iv) Apoyar los mensajes de la lucha contra el terrorismo; v) Luchar contra la radicalización y la captación de terroristas en internet; vi) Formar, capacitar e involucrar a profesionales de primera línea en distintos sectores; vii) Ayudar a las personas y a la sociedad civil a mejorar su capacidad de resistencia; viii) Apoyar las iniciativas de desvinculación; ix) Apoyar una investigación más detallada de las tendencias y los retos de la radicalización y la captación de terroristas, y x) Concertar los trabajos internos y externos contra la radicalización. Ibid.

37 COM (2016) 379 final. 
violentas y radicalizadas. Por ello, en estos últimos años la Comisión Europea ha financiado proyectos de investigación sobre el proceso de radicalización y los factores que pueden conducir al terrorismo ${ }^{38}$. Esta investigación desde el mundo académico se suma a la inteligencia penal elaborada por Europol en sus informes de la amenaza, los denominados EU Terrorism Situation and Trend Report (TE-SAT), que sientan las bases de la intervención policial europea en materia de terrorismo, tanto a nivel operativo como estratégico, guiando la respuesta a la radicalización desde la aportación del ámbito de la justicia penal y policial (véase el siguiente apartado).

12. Estrictamente en el terreno de la prevención de la radicalización violenta, uno de los pilares de la intervención comunitaria ha estado centrado en el autocontrol de los medios de comunicación y su papel para evitar la propagación de la retórica extremista y del discurso del odio a través de internet $^{39}$. A tal fin, en línea con las acciones previstas en la Agenda Europea de Seguridad, la Comisión Europea - apoyada por la Red de la UE para la Sensibilización frente a la Radicalización (RSR) ${ }^{40}$ - ha promovido foros de debate y conferencias de alto nivel sobre el rol de los medios de comunicación en la prevención de la radicalización violenta en los que han participado no solamente responsables políticos de las diferentes instituciones europeas y estatales, sino que han aglutinado igualmente a representantes de compañías como Facebook, Google, Microsoft y Twitter. Así, en diciembre de 2015, la Comisión Europea puso en marcha el Foro de Internet de la UE y, en mayo de 2016, publicó el Código de Conducta solicitado por el Consejo tras los ataques terroristas de marzo de ese año en Bruselas ${ }^{41}$. Este Código, completado con la normativa europea penal, pretende sentar las bases de un com-

38 Así, por ejemplo, el topic «Contemporary radicalization trends and their implications for Europe» (REV-INEQUAL-02-2016) del Programa «Horizonte 2020» estaba destinado a financiar proyectos europeos que abordaran la radicalización, propusieran nuevas metodologías de estudio e identificaran tendencias en los procesos seguidos por individuos desde diferentes disciplinas, fundamentalmente en relación al alcance, orígenes, causas y dinámicas de radicalización. En la misma convocatoria, otros topics abordaban de manera indirecta las desigualdades sociales y cómo hacerles frente desde el ámbito socioeconómico y las políticas migratorias, mientras que otras convocatorias hacían referencia al papel de la UE en el mundo para luchar contra la radicalización y la prevención del terrorismo en sus relaciones exteriores (ENG-GLOBALLY-01-2017). Pueden consultarse las diferentes convocatorias en el Portal del Participante: http://ec.europa.eu/research/participants/portal/desktop/en/home.html.

39 Sobre la faceta de comunicación de los grupos terroristas y el papel de internet en la yihad mediática, véase TORRES SORIANO, M., "Terrorismo yihadista y nuevos usos de Internet: la distribución de propaganda», ARI, Real Instituto Elcano, de 9 de julio de 2009, núm. 110.

40 Establecida por la Comisión Europea en 2011, esta Red conecta organizaciones clave y redes de actores locales comprometidos con la prevención de la radicalización terrorista y el extremismo violento, incluyendo profesionales en primera línea y expertos sobre el terreno (trabajadores sociales y sanitarios, educadores, organizaciones de la sociedad civil, autoridades locales, fiscales, policía, centros de investigación, etc.). Su finalidad principal es servir de plataforma de intercambio de buenas prácticas en materia de prevención y apoyar a los EEMM en el diseño e implementación de sus políticas nacionales. Más información en: https://ec.europa.eu/home-affairs/what-we-do/networks/radicalisation_awareness_network_en.

41 CONSEJo de la UNIÓN EuROPEA, «Declaración conjunta de los ministros de Justicia y Asuntos de Interior de la UE y los representantes de las instituciones de la UE con motivo de los atentados terroristas perpetrados en Bruselas el 22 de marzo de 2016», 7371/16, de 24 de marzo de 2016, punto 7. 
promiso público conjunto para neutralizar el discurso del odio en internet, obligándose las compañías de telecomunicaciones a colaborar activamente con las instituciones y actores de la sociedad civil y liderar la lucha contra la propagación de la incitación al odio, identificar contenidos no autorizados que promuevan la violencia y retirarlos de la red ${ }^{42}$. Además, la UE ha lanzado iniciativas que pretenden poner la "contrarréplica» al discurso radicalizado e impedir que estos mensajes lleguen a jóvenes en riesgo. Para ello, aparte de los compromisos adquiridos por las partes mediante el Código de Conducta para promover una contrarréplica eficaz, en septiembre de 2016, la RSR inició la campaña Exit Hate con el fin de difundir discursos alternativos y testimonios personales que permitan a personas en riesgo de radicalización (o radicalizadas) romper con el círculo vicioso de radicalización, agresión y reacciones violentas ${ }^{43}$, abarcando todo tipo de extremismo violento y procesos de radicalización. No obstante, esta contra-narrativa comunitaria no llega a incorporar plenamente las lecciones aprendidas a nivel local ${ }^{44}$, un nivel de gobierno ausente, en general, en el planteamiento preventivo de la UE.

13. Otro de los ejes esenciales de las medidas preventivas ha sido el empoderamiento de la sociedad civil y el diálogo interreligioso. En cuanto al primero, la Comisión publicó, en marzo de 2017, el Programa «Empoderamiento de la Sociedad Civil» para ayudar a organizaciones de la sociedad civil a desarrollar narrativas alternativas «eficaces» a la propaganda terrorista en la red a través de apoyo financiero, asesoramiento y formación. Este programa, organizado por la RSR, completa las iniciativas impulsadas en el marco del Código de Conducta y por otros programas, como «Derechos, Igualdad y Ciudadanía» ${ }^{45}$, que financia proyectos destinados a propiciar un mejor entendimiento entre comunidades - incluidas las religiosas- para prevenir y combatir el racismo y la xenofobia mediante actividades interreligiosas e interculturales, inscritas en el mandato del art. 17 del TFUE ${ }^{46}$. En este contexto de diálogo interreligioso, en diciembre de 2015, la Comisión Europea nombró a Katharina von Schnurbein Coordinadora de la lucha contra el antisemitismo, y a David Friggieri Coordinador de la lucha contra el odio antimusulmán. Ambos, actuando como puntos de contacto para las respectivas comunidades y siendo miembros del Grupo de Alto Nivel para combatir el racismo y la xenofobia ${ }^{47}$, habrían de contribuir igualmente a la contra-narrativa de la UE y a la implementación de la normativa comunitaria por medio del entendimiento interreligioso desde el impulso de la sociedad civil y las comunidades, hasta la fecha uno de los principales límites del enfo-

42 Code of Conduct on Countering Illegal Hate Speech Online, su texto está disponible en: http:// ec.europa.eu/justice/fundamental-rights/files/hate_speech_code_of_conduct_en.pdf.

43 Más información en: http://www.exithate.com/.

44 Sobre el papel de los entes locales en la prevención de la radicalización en los EEMM, véanse CoOlsaet, R., Jordán Enamorado, J. y Schmid, A. P., op. cit., nota 7.

45 Más información en: http://ec.europa.eu/justice/grants1/programmes-2014-2020/rec/index_en.htm.

46 Art. 17.3 del TFUE: «Reconociendo su identidad y su aportación específica, la Unión mantendrá un diálogo abierto, transparente y regular con dichas iglesias y organizaciones».

47 Más información en: http://ec.europa.eu/newsroom/just/item-detail.cfm?item_id=51025. 
que de la UE contra la radicalización, al carecer de instrumentos eficaces de empoderamiento y participación en la toma de decisiones y acciones.

14. Por último, la UE ha puesto en marcha diversas iniciativas para prevenir la radicalización violenta desde los ámbitos de la formación, la juventud y la educación. El 17 de marzo de 2015, la Comisión Europea y los ministros de Educación de la UE adoptaron la Declaración de París, por la que se comprometían a reforzar sus acciones y promover la inclusión social, asegurándose que la juventud europea adquiría competencias sociales, cívicas e interculturales y reforzar su pensamiento crítico, especialmente ante los discursos de incitación al odio y la violencia en internet. Este compromiso, recogido en la Comunicación de la Comisión de junio de 2016 y cuyo seguimiento está encomendado a un grupo de trabajo multidisciplinar ${ }^{48}$, engloba varias áreas de trabajo en las que la UE dispone de competencias subsidiarias: la promoción de la educación inclusiva y los valores comunes y la instauración de «medidas que permitan la pronta identificación y prevención de la exclusión social, el acoso, el abandono escolar temprano y los primeros signos de radicalización que puedan conducir al extremismo violento», en particular en medios desfavorecidos y población en riesgo ${ }^{49}$, apelando a instrumentos de apoyo en materia de empleo y juventud ${ }^{50}$; acciones específicas para la integración de nacionales de terceros Estados recién llegados en las comunidades de acogi$\mathrm{da}^{51}$; y la formación de trabajadores en primera línea en escuelas y prisiones, para lo cual ha recurrido a programas como Erasmus+, cuyas convocatorias en los últimos años han incluido la prevención de la radicalización y el extremismo violento entre sus prioridades ${ }^{52}$. Asimismo, la UE ha apoyado las políticas de los EEMM en esta materia a través del auxilio prestado por los principales actores en este terreno (la Red Europea de Formación Judicial ${ }^{53}$,

48 Para más información: http:/lec.europa.eu/education/policy/strategic-framework/expert-groups/ citizenship-common-values_en.

49 Consejo de la Unión Europea, «Conclusiones del Consejo y de los Representantes de los Gobiernos de los Estados miembros, reunidos en el Consejo, sobre la inclusión en la diversidad para conseguir una educación de alta calidad para todos - Conclusiones del Consejo (17 de febrero de 2017)», 6356/17, Bruselas, de 17 de febrero de 2017, p. 5. Asimismo, con carácter específico desde el ámbito de la juventud y la educación, «Prevención de la radicalización que conduce al extremismo violento - Conclusiones del Consejo y de los Representantes de los Gobiernos de los Estados miembros reunidos en el seno del Consejo (21 de noviembre de 2016)», 14276/16, de 23 de noviembre de 2016.

50 Por ejemplo, la «Garantía Juvenil» y el «Fondo Social Europeo» son instrumentos de la UE que apoyan las políticas de los EEMM en materia de inclusión social, juventud y empleo. Más información: http://ec.europa.eu/social/home.jsp?langId=es.

51 En línea con el Plan de acción para la integración de nacionales de terceros países [COM (2016) 377 final, de 7 de junio de 2016].

52 En las convocatorias de Erasmus+ para los años 2016 y 2017 se ha realizado especial énfasis en la financiación de proyectos destinados a fomentar los valores comunes europeos, impulsar la integración social, mejorar la comprensión intercultural y un sentimiento de pertenencia a la comunidad social, así como para evitar la radicalización violenta. Estos proyectos están destinados tanto a formar a los cuerpos docentes y funcionarios de prisiones para abordar estos temas en entornos difíciles, como a permitir la movilidad de estudiantes en riesgo y la transmisión de estos valores comunes. Puede consultarse más información en la Guía del Programa: http://ec.europa.eu/programmes/erasmus-plus/ resources_en.

53 http://www.ejtn.eu/. 
la Escuela Europea de Policía ${ }^{54}$, Eurojust ${ }^{55}$ y la RSR) y de la financiación ofrecida en el marco del Programa "Justicia» ${ }^{56}$, que sufraga la formación de jueces y actividades de intercambio de experiencias y buenas prácticas entre las entidades competentes (jueces, responsables políticos, cuerpo penitenciario y juristas) en temas como la mejora del acceso a la justicia, asistencia a las víctimas y alternativas a la detención en el marco de la justicia juvenil que eviten que los jóvenes que entren en prisión sean captados por terroristas en las cárceles. En este punto, además de ser una intervención solicitada por el Consejo entre las medidas para impedir la radicalización que conduce al terrorismo y el extremismo violento en los espacios de reclusión ${ }^{57}$, la UE recoge finalmente entre sus áreas de actuación una de las principales preocupaciones del Consejo de Europa, cual es la de contrarrestar la propagación de la propaganda radical en las cárceles como medida preventiva ${ }^{58}$, dada la incidencia de este discurso radical en las prisiones europeas ${ }^{59}$.

\subsubsection{Las acciones represivas contra la radicalización: intervención desde el sector de la seguridad}

15. La prevención de la radicalización en la UE también ha recibido respuesta desde los ámbitos policial y de justicia penal en el marco del ESLJ. En primer lugar, los informes de amenaza de Europol (TE-SAT) sientan las bases de la inteligencia penal sobre el fenómeno terrorista a nivel de la UE y, por tanto, sirven para guiar la actuación europea en aquellos ámbitos en los que se precisa su intervención directa para mejorar la coordinación entre EEMM, como la cooperación policial y el intercambio de información y datos entre autoridades del orden público. En estos informes, elaborados desde 2007, se han analizado las tendencias en el proceso de radicalización y los grupos en riesgo y, en general, la evolución del terrorismo en la UE. Por ejemplo, en el último informe publicado, de 2016, Europol destaca el papel de los «combatientes extranjeros» en el proceso de radicalización yihadista y el reclutamiento de nuevos terroristas entre ciudadanos europeos, especialmente

54 https://www.cepol.europa.eu/.

55 http://www.eurojust.europa.eu/.

56 http://ec.europa.eu/justice/grants1/programmes-2014-2020/justice/index_en.htm.

57 Consejo de la Unión Europea, «Conclusiones del Consejo de la Unión Europea y de los Representantes de los Estados miembros, reunidos en el Consejo, sobre la mejora de la respuesta de la justicia penal a la radicalización que conduce al terrorismo y al extremismo violento (20 de noviembre de 2015)», 14419/15, Bruselas, de 20 de noviembre de 2015.

58 Además de incluirse en el Plan de Acción [CM (2015) 74 add final, de 19 de mayo de 2015], el Consejo de Europa ha elaborado una Guía para los servicios de prisiones y libertad vigilada, adoptada por el Consejo de Ministros el 2 de marzo de 2016 [CM/Del/Dec(2016)1249]. Más información sobre este asunto en: http://www.coe.int/en/web/prison.

59 Véase Radicalisation Awareness Network, Preventing Radicalization to Terrorism and Violent Extremism. Approaches and Practices, 2017, disponible en: https:/lec.europa.eu/home-affairs/what-wedo/networks/radicalisation_awareness_network. Para el caso español, véase GUTIÉRREZ, J. A., JoRDÁN, J. y TruJILlo, H., «Prevención de la radicalización yihadista en las prisiones españolas. Situación actual, retos y disfunciones del sistema penitenciario», Athena Intelligence Journal, vol. 3, 2008, núm. 1, pp. 1-12. 
en entornos desfavorecidos y en prisiones, además de señalar el «riesgo real e inminente» de que "parte de la diáspora de refugiados sirios (musulmanes sunníes) se vuelvan vulnerables a la radicalización una vez en Europa y sean objetivo específico de reclutadores islamistas extremistas» ${ }^{60}$.

16. Debido al reciente foco sobre los «combatientes extranjeros», aparte de consolidar las fronteras («inteligentes») exteriores ${ }^{61}$, en estos últimos años la UE ha puesto especial énfasis en sacarle el máximo partido y reforzar las normas existentes relativas al intercambio de datos e información entre autoridades estatales del orden público ${ }^{62}$ y entre estas y los operadores privados, como las aerolíneas ${ }^{63}$. Si bien ya dentro de los pilares prevenir y perseguir de la Estrategia europea contra el Terrorismo, algunas de las nuevas iniciativas legislativas en negociación son especialmente relevantes en el ámbito de la prevención de la radicalización desde el sector de la seguridad ${ }^{64}$, en particular la relativa a la ampliación del Sistema Europeo de Información de Antecedentes Penales (ECRIS) a los nacionales de terceros países, al ser reconocido por el Consejo como uno de los instrumentos que contribuirían a la respuesta de la justicia penal frente a la radicalización que conduce al terrorismo y el extremismo violento ${ }^{65}$. De esta forma, las autoridades nacionales podrán,

${ }^{60}$ Europol, European Union Terrorism Situation and Trend Report (TE-SAT) 2016, La Haya, 2016, p. 7 (traducción propia).

${ }^{61}$ En este sentido, la última propuesta es la «Comunicación de la Comisión al Parlamento Europeo y al Consejo. Sistemas de información más sólidos e inteligentes para la gestión de las fronteras y la seguridad», COM (2016) 205 final, Bruselas, de 6 de abril de 2016.

${ }_{62}$ Existen numerosos instrumentos legislativos para la mejora del intercambio de información e inteligencia penal entre las autoridades competentes de los EEMM y entre estas y los actores del ELSJ. Dichos instrumentos pretenden la puesta en marcha del modelo europeo de actuación policial basado en la inteligencia por medio de la mejora de la fluidez del intercambio de información entre las autoridades competentes, tanto a nivel estratégico (preventivo) como operativo (reactivo). Por su relevancia para el presente estudio, son de destacar la Decisión marco 2006/960/JAI, de 18 de diciembre, sobre la simplificación del intercambio de información e inteligencia entre los servicios de seguridad de los Estados miembros de la Unión Europea (DO L núm. 386, de 29 de diciembre de 2006, pp. 89-100) ( Iniciativa Sueca»); la Decisión 2008/615/JAI, del Consejo, de 23 de junio, sobre la profundización de la cooperación transfronteriza, en particular en materia de lucha contra el terrorismo y la delincuencia transfronteriza (DO L núm. 210, de 6 de agosto de 2008, pp. 1-11) («Decisión Prüm); y la Decisión 2008/616/JAI, del Consejo, de 23 de junio, relativa a la ejecución de la Decisión 2008/615/JAI sobre la profundización de la cooperación transfronteriza, en particular en materia de lucha contra el terrorismo y la delincuencia transfronteriza (DO L núm. 210, de 6 de agosto de 2008, pp. 12-72) («Decisión de implementación de Prüm»).

63 Directiva 2016/681, del Parlamento Europeo y del Consejo, de 27 de abril, relativa a la utilización de datos del registro de nombres de los pasajeros (PNR) para la prevención, detección, investigación y enjuiciamiento de los delitos de terrorismo y de la delincuencia grave ( $D O$ L núm. 119, de 4 de mayo de 2016, pp. 132-149); y Directiva 2004/82/CE, del Consejo, de 29 de abril, sobre la obligación de los transportistas de comunicar los datos de las personas transportadas ( $D O \mathrm{~L}$ núm. 261, de 6 de agosto de 2004, pp. 24-27) («Directiva API»).

${ }^{64}$ En particular, las propuestas en negociación son: el Sistema de Entradas y Salidas (SES) [COM (2016) 196 final - 2016/0105 (COD)]; el Sistema Europeo de Información y Autorización de Viajes (SEIAV) [COM (2016) 731 final - 2016/0357 (COD)]; la Directiva sobre el blanqueo de capitales y la financiación del terrorismo [COM (2016) 450 final - 2016/0208 (COD)]; el Sistema Europeo de Información de Antecedentes Penales (ECRIS) [COM (2016) 7 final - 2016/0002 (COD)]; y el Reglamento sobre la privacidad y las comunicaciones electrónicas (privacidad electrónica) [COM (2017) 10 final - 2017/0003 (COD)].

65 Consejo de la Unión EuRopea, op. cit., nota 57. 
de adoptarse la propuesta, consultar y comparar en las bases de datos información sobre delitos de nacionales de terceros Estados supuestamente radicalizados o que apoyan la propagación de la propaganda extremista. A esta iniciativa legislativa hemos de añadir otra relativa al refuerzo del Sistema de Información Schengen (SIS) desde el ámbito de la justicia penal ${ }^{66}$, lo que acabaría ampliando considerablemente el recurso a este tipo de bases de datos existentes en la actualidad - con todos los problemas de protección de datos que ello conlleva- ${ }^{67}$.

17. Por otra parte, la UE ha recurrido al Derecho penal para la tipificación de determinados delitos relacionados con el extremismo violento y la radicalización, en particular por medio de internet y otros medios de comunicación. En este contexto, la Decisión marco de 2008 incluye entre los delitos a tipificar por los EEMM la incitación al odio y la violencia en Internet ${ }^{68}$, que completa las disposiciones al respecto de las Directivas de servicios de comunicación audiovisual ${ }^{69}$ y comercio electrónico ${ }^{70}$. Además, las autoridades nacionales pueden recurrir a la Unidad de Notificación de Contenidos de Internet, en el seno del Centro Europeo de Lucha contra el Terrorismo de Europol $^{71}$, y a Eurojust para facilitar la identificación y retirada o bloqueo de contenidos que inciten al odio y al extremismo violento o constituyan una provocación pública a la comisión de un delito de terrorismo, en virtud de

66 «Propuesta de Reglamento del Parlamento Europeo y del Consejo relativo al establecimiento, funcionamiento y utilización del Sistema de Información de Schengen (SIS) en el ámbito de la cooperación policial y judicial en materia penal, por el que se modifica el Reglamento 515/2014 y se deroga el Reglamento 1986/2006, la Decisión 2007/533/JAI del Consejo, y la Decisión 2010/261/UE de la Comisión», COM(2016) 883 final - 2016/0409 (COD), Bruselas, de 21 de diciembre de 2016.

${ }_{67}$ Para un análisis de las implicaciones de la nueva normativa europea de protección de datos y el ELSJ, véase Blasi Casagran, C., Global Data Protection in the Field of Law Enforcement. An EU Perspective, Nueva York, Routledge, 2017, en particular pp. 36-52.

68 Decisión marco 2008/913/JAI, del Consejo, de 28 de noviembre, relativa a la lucha contra determinadas formas y manifestaciones de racismo y xenofobia mediante el Derecho penal (DO L núm. 328, de 6 de diciembre de 2008, pp. 5-8).

69 Directiva 2010/13/UE, del Parlamento Europeo y del Consejo, de 10 de marzo, sobre la coordinación de determinadas disposiciones legales, reglamentarias y administrativas de los Estados miembros relativas a la prestación de servicios de comunicación audiovisual (Directiva de servicios de comunicación audiovisual) (DO L núm. 95, de 15 de abril de 2010, pp. 1-24). A finales de mayo de 2016, la Comisión Europea presentó una propuesta para revisar esta Directiva por la que se introduciría la obligación de los EEMM de velar por que los proveedores de plataformas de distribución de vídeos adopten medidas adecuadas para: i) proteger a los menores frente a los contenidos nocivos, y ii) proteger a todos los ciudadanos contra la incitación a la violencia o al odio. Además, se introduce la obligación de que las plataformas de distribución adopten, entre otras medidas, la notificación y el marcado de contenidos nocivos, así como el control por parte de organismos estatales del cumplimiento de los códigos de conducta [COM (2016) 287 final - 2016/0151 (COD)].

${ }^{70}$ Directiva 2000/31/CE, del Parlamento Europeo y del Consejo, de 8 de junio, relativa a determinados aspectos jurídicos de los servicios de la sociedad de la información, en particular el comercio electrónico en el mercado interior (Directiva sobre el comercio electrónico) (DO L núm. 178, de 17 de julio de 2000, pp. 1-16).

71 Creada en julio de 2015, esta Unidad, en el seno de Europol, actúa como centro de conocimiento técnico, ayudando a las autoridades estatales a identificar y eliminar o bloquear los contenidos extremistas violentos en línea, en cooperación con las compañías de telecomunicaciones, como se dispone en el Código de Conducta y la normativa antiterrorista europea. Más información en: www.europol. europa.eu. 
las disposiciones de la nueva Directiva contra el terrorismo, que insiste igualmente en la combinación de los medios a disposición de la UE para atajar la radicalización ${ }^{72}$. A esta regulación se añaden las normas contra la financiación del terrorismo y el blanqueo de capitales ${ }^{73}$ y las relativas al embargo y decomiso de los productos del delito ${ }^{74}$, en particular en cuanto que la iniciativa de reforma del primero prevé medidas de refuerzo de los instrumentos de prepago y monedas virtuales que pueden ser sospechosos de financiación del terrorismo, y el segundo incorpora al marco de la lucha contra el terrorismo medidas de embargo y decomiso importadas de la prevención y represión del crimen organizado transnacional, tras constatarse el creciente recurso a actividades delictivas por parte de grupos terroristas para financiarse y los nexos entre ambos fenómenos criminales ${ }^{75}$.

\subsubsection{Las acciones de desvinculación, rehabilitación y reintegración}

18. En el ámbito de la desvinculación y reintegración, entramos en un terreno de competencia exclusiva de los EEMM donde el apoyo de la UE es bastante más reducido por reciente y subsidiario. Por primera vez, a iniciativa de la Comisión Europea ${ }^{76}$, la Estrategia revisada contra la radicalización (2014) introduce en el marco de actuación de la UE la necesidad de apoyar

72 Directiva 2017/541, del Parlamento Europeo y del Consejo, de 15 marzo, relativa a la lucha contra el terrorismo y por la que se sustituye la Decisión marco 2002/475/JAI, del Consejo, y se modifica la Decisión 2005/671/JAI, del Consejo (DO L núm. 88, de 31 de marzo de 2017, pp. 6-21), en particular su art. 21 y el considerando 31 .

73 Directiva 2015/849, del Parlamento Europeo y del Consejo, de 20 de mayo, relativa a la prevención de la utilización del sistema financiero para el blanqueo de capitales o la financiación del terrorismo, y por la que se modifica el Reglamento 648/2012, del Parlamento Europeo y del Consejo, y se derogan la Directiva 2005/60/CE, del Parlamento Europeo y del Consejo y la Directiva 2006/70/ CE de la Comisión (DO L núm. 141, de 5 de junio de 2015, pp. 73-117). Adicionalmente, la Directiva 2015/2366, del Parlamento Europeo y del Consejo, de 25 de noviembre, sobre servicios de pago en el mercado interior y por la que se modifican las Directivas 2002/65/CE, 2009/110/CE y 2013/36/UE y el Reglamento 1093/2010 y se deroga la Directiva 2007/64/CE (DO L núm. 337, de 23 de diciembre de 2015, pp. 35-127). Véase sobre esta última: GonZÁlez Fuster, G., «EU Data Protection and Future Payment Services», en Gimigliano, G. (ed.), Bitcoin and Mobile Payments: Constructing a European Union Framework, Palgrave Macmillan, pp. 181-201. En julio de 2016, la Comisión Europea presentó una nueva propuesta de modificación destinada a reforzar el marco comunitario, particularmente en materia de control de los instrumentos de prepago, transacciones utilizando monedas virtuales y consolidación de las competencias de acceso a la información por parte de las Unidades de Investigación Financieras [COM (2016) 450 final - 2016/0208 (COD)], en línea con el mandato derivado de la Agenda Europea de Seguridad y del Plan de Acción para intensificar la lucha contra la financiación del terrorismo $[\operatorname{COM}(2016) 50$ final].

74 Directiva 2014/42/UE, del Parlamento Europeo y del Consejo, de 3 de abril, sobre el embargo y el decomiso de los instrumentos y del producto del delito en la Unión Europea (DO L núm. 127, de 29 de abril de 2014, pp. 39-50).

75 Véase, por ejemplo, West SANDS AdVISORY, Europe's Crime-Terror Nexus: Links between terrorist and organised crime groups in the European Union, Estudio solicitado por el Parlamento Europeo, Bruselas, 2012, disponible en: http://www.europarl.europa.eu/studies.

76 COM (2013) 941 final, Bruselas, de 15 de enero de 2014, punto 2.5 «Desarrollar "estrategias de salida" que ayuden a los individuos a renunciar al extremismo violento: ventajas para los Estados miembros". 
iniciativas de desvinculación de los individuos radicalizados y hace hincapié en que los EEMM estudien la posibilidad de elaborar y desarrollar «estrategias de salida» que ayuden a que individuos ya radicalizados se desvinculen del grupo y, en último término, renuncien a la violencia y la ideología subyacente. Dichas estrategias deberán, asimismo, adaptarse a los contextos sociocultural e individual específicos, por lo que la UE pone a disposición de las autoridades estatales el apoyo de la RSR en la elaboración y diseño de los programas de intervención y reinserción social ${ }^{77}$. La labor comunitaria para apoyar las medidas de desvinculación estatales se reduce, no obstante, a la financiación de proyectos con cargo al «Fondo de Seguridad Interior» ${ }^{78}$ para programas de desvinculación dentro y fuera de las prisiones - espacios en los que inciden la mayoría de las actuaciones observadas en los EEMM ${ }^{79}$-, debido al carácter residual de las medidas de la UE, puramente entre el soft law y el intercambio de buenas prácticas a través de la RSR. Junto a la ausencia del nivel de gobierno local en la respuesta comunitaria, esta intervención tardía y subsidiaria supone otro de los principales límites al papel de la UE en el terreno preventivo, pues, como indica Rik Coolsaert, en materia de desvinculación «los enfoques a medida tienen las mayores oportunidades de resultar exitosos si se persiguen a nivel local y se cumplen [...] tres condiciones»: requiere de un enfoque personalizado, por el que la persona interesada es vista como un individuo, no como miembro de un grupo (hostil); dicha persona ha de ser receptiva al debate, de ahí la importancia de identificar mentores y canales de comunicación para ganarse su confianza; y se le ofrece una perspectiva para reconectarlo con la sociedad local ${ }^{80}$. A día de hoy, la UE está dando los primeros pasos: pero, sin incorporar a los entes locales en su intervención y abordar la radicalización desde una perspectiva verdaderamente multidimensional, no está en posición de proporcionar ninguna de las tres condiciones necesarias para que las «estrategias de salida» funcionen en la práctica a pesar del cambio de enfoque operado por la revisión de la Estrategia contra la radicalización en 2014.

\section{LA PREVENCIÓN DE LA RADICALIZACIÓN TERRORISTA EN LA ESTRATEGIA EXTERIOR DE LA UNIÓN EUROPEA}

19. Desde que se pusieran en marcha, las medidas de la UE para prevenir la radicalización han enfatizado la necesidad de abordar este fenómeno también en la acción exterior de la UE, en el seno de organismos internacionales como la ONU y en sus relaciones con terceros Estados. En 2005, Consejo y Comisión coincidieron en la importancia de una Europa activa en la escena

\footnotetext{
77 CONSEJO dE LA Unión EuROPEA, «Estrategia revisada de la UE para luchar contra la radicalización y la captación de terroristas», 9956/14, de 19 de mayo de 2014, p. 11.

78 Información disponible en: https://ec.europa.eu/home-affairs/financing/fundings/security-andsafeguarding-liberties/internal-security-fund-police_en.

79 Véase nota 59.

${ }^{80}$ Coolsaet, R., op. cit., nota 7, p. 47 (traducción propia).
} 
internacional que promueva «la buena gobernanza, los derechos humanos, la democracia, la educación y la prosperidad económica a través (del) diálogo político y de los programas de asistencia» como medio para luchar contra la radicalización terrorista ${ }^{81}$. Diez años más tarde, el Consejo Europeo volvería a incidir en la necesidad de impulsar las medidas para prevenir la radicalización terrorista y el extremismo violento en el marco de las relaciones con sus socios, en particular abordando las crisis y los conflictos regionales, mediante una mayor implicación con terceros países en cuestiones de seguridad y de lucha contra el terrorismo, una actuación internacional constante y coordinada con las Naciones Unidas y el Foro Mundial contra el Terrorismo y el diálogo entre culturas y civilizaciones ${ }^{82}$.

20. Aparte de un activo papel en el seno de instituciones internacionales, como la Organización de las Naciones Unidas (ONU) ${ }^{83}$, la UE ha desplegado una ingente actividad en su vecindario próximo en cuatro cuestiones clave que ha enmarcado en el conjunto de sus relaciones con Estados terceros considerados prioritarios: la gestión de las fronteras exteriores, la promoción del desarrollo económico, el impulso del diálogo intercultural y, en menor medida, el empoderamiento de la sociedad civil. De esta forma, la prevención de la radicalización ha sido un tema transversal en la acción exterior de la UE como medio principal para atajar el terrorismo en el entorno de sus fronteras y proteger su espacio de seguridad interior ante una periferia «inestable» ${ }^{84}$, siendo capaz de incorporar en sus acuerdos con terceros «cláusulas antiterroristas» de alcance general ${ }^{85}$. En este sentido, la Estrategia revisada contra la

81 Consejo de la Unión Europea, op. cit., nota 30, p. 5. En la revisión de 2014, el Consejo añadiría la promoción del Estado de Derecho y la reforma del sector de la seguridad entre sus prioridades en el exterior para combatir la radicalización terrorista. Los nexos a las dimensiones interna y externa en la política contra el terrorismo de la UE y, en particular, en materia de prevención de la radicalización será un tema recurrente en el discurso de las instituciones, si bien con resultados modestos, dadas las disparidades entre la dimensión interior y la exterior. Entre otros documentos, estos nexos se reafirmaron posteriormente en la «Estrategia para la dimensión exterior de la JAI: libertad, seguridad y justicia a escala mundial», 15446/05, de 6 de diciembre de 2005, y la Estrategia Global de Seguridad (2016).

82 Reunión informal de los jefes de Estado o de Gobierno en Bruselas, de 12 de febrero de 2015, Declaración de los miembros del Consejo Europeo.

${ }^{83}$ La UE en su conjunto y, de manera individualizada, sus EEMM han contribuido activamente a promover un rol activo de la ONU contra el terrorismo y la prevención de la radicalización terrorista. Así, por ejemplo, la Resolución del Consejo de Seguridad 1624 (2005) fue una iniciativa del Reino Unido para prevenir la radicalización tras los atentados del 7-J, prestando especial atención al contexto social que puede conducir a la expansión del terrorismo. Además, participa y financia proyectos de la Oficina de Naciones Unidas contra la Droga y el Delito (ONUDD) y colabora activamente en los trabajos de la Dirección Ejecutiva del Comité contra el Terrorismo. Para un análisis de la relación entre la ONU y la UE en la lucha contra el terrorismo, véase CASTRO RUANO, J. L., «La interacción Naciones Unidas y Unión Europea en materia de lucha contra el terrorismo global», en Blanc ALTEMIR, A. (dir.), Las relaciones entre las Naciones Unidas y la Unión Europea: seguridad, cooperación y derechos humanos, Madrid, Tecnos, 2013, pp. 272-300.

84 «Muchos de los problemas de seguridad de hoy en día tienen su origen en la inestabilidad en la vecindad inmediata de la UE y en formas cambiantes de radicalización, violencia y terrorismo. Las amenazas son cada vez más variadas e internacionales, y cada vez más de naturaleza transfronteriza e intersectorial»: véase COM (2015) 185, Estrasburgo, de 28 de abril de 2015, p. 2.

${ }_{85}$ Así, por ejemplo, en la revisión del Acuerdo de Cotonú en 2005, las Partes introdujeron un art. 11.a) relativo a la lucha contra el terrorismo por el que se comprometían a intercambiar informa- 
radicalización de 2014 confirmaría el papel que las políticas de inmigración y visados, junto con el refuerzo de la gestión de las fronteras exteriores, han tenido como los principales instrumentos de los que la Unión dispone para abordar la prevención de la radicalización terrorista en sus relaciones exteriores, a la que ha venido a sumarse la contribución de la («securitizada») ${ }^{86}$ política de cooperación al desarrollo (PCD), ahondando en el nexo seguridaddesarrollo subyacente al enfoque preventivo de la UE.

21. La prevención de la radicalización del terrorismo ha sido incluida, por tanto, en cada una de estas políticas como un tema transversal de las relaciones exteriores de la UE, en particular en relación con determinadas áreas geográficas prioritarias para la consecución de sus intereses en materia de seguridad interior. En primer lugar, la progresiva adopción del acervo comunitario en el marco de la Política de Ampliación se ha convertido en un instrumento esencial en la implementación de las medidas antiterroristas y para la prevención de la radicalización en los Balcanes occidentales, cuyo refuerzo forma parte integral de las medidas para proteger la seguridad interior de la UE desde que se iniciara el proceso de estabilización en la zona ${ }^{87}$. Asimismo, las últimas reformas de la Política Europea de Vecindad (PEV) prevén medidas contra la radicalización en el marco de las relaciones con Estados terceros, además de solicitar reformas en el sector de la seguridad y la gestión de fronteras a cambio de asistencia técnica y concesiones en el contexto de la política de migración y visados, convirtiéndose en un instrumento clave en la externalización de los objetivos de seguridad interior de la UE. En concreto, la última revisión de la PEV (noviembre de 2015) propuso intensificar el diálogo político con los socios de las regiones englobadas con el fin de reforzar las capacidades de estos terceros Estados frente a la amenaza terrorista y la prevención de la radicalización mediante el apoyo en los ámbitos de la educación y la juventud, así como medidas adicionales destinadas a la reforma del sector de la seguridad y la gestión de las fronteras, destacando la pobreza y la percepción de desigualdades como factores que pueden colocar en posición de vulnerabilidad a los jóvenes ante la radicalización terrorista ${ }^{88}$.

ción sobre los grupos y redes de apoyo a terroristas. Similares disposiciones existen en los Acuerdos Euromediterráneos con Egipto (2004) y Argelia (2005).

${ }^{86}$ De esta opinión, véanse: Duffield, M., "Governing the Borderlands: Decoding the Power of Aid», Disasters, vol. 25, 2001, núm. 4, pp. 308-320; y GIBERT, M. V., «The securitisation of the EU's development agenda in Africa: insights from Guinea-Bissau», Perspectives on European Politics and Society, vol. 10, 2009, núm. 4, pp. 621-637.

${ }^{87}$ La importancia concedida a los países de la región en la protección del orden público y la seguridad interior de la UE parte, esencialmente, de la Cumbre de Zagreb (2000) y del Consejo Europeo de Salónica (2003), reuniones en las que se reconocía la importancia de la cooperación con -y dentro de- la región en materia de asuntos de Justicia e Interior y la lucha contra el crimen organizado transnacional y el terrorismo. Más recientemente, «Conclusiones del Consejo sobre el refuerzo de la dimensión exterior de la seguridad interior de la UE en los Balcanes Occidentales, especialmente por medio de la gobernanza integradora de la seguridad interior - Conclusiones del Consejo ( 8 de diciembre de 2016)», 15413/16, Bruselas, de 9 de diciembre de 2016.

${ }_{88}$ «La pobreza, la desigualdad, la percepción de la existencia de injusticias, la corrupción, un débil desarrollo económico y social y la falta de oportunidades, especialmente para los jóvenes, pueden 
22. Además de estas regiones, la UE ha mostrado una creciente preocupación por el desarrollo y expansión del terrorismo en África, especialmente en relación a las conexiones con el terrorismo internacional en el Sahel ${ }^{89}$ y la prevención de la radicalización en la ribera sur del Mediterráneo tras el incremento de la inestabilidad sociopolítica posterior a la «Primavera Árabe» ${ }^{90}$. Aparte del Sahel, con una dinámica y atención particulares en la PESC/PCSD, el norte de África se ha convertido en foco de la preocupación de las instituciones de la UE. En general, la cooperación antiterrorista con el vecindario en el Sur se ha centrado en cuatro áreas, coincidentes con las preconizadas por la $\mathrm{ONU}^{91}$ : fortalecimiento de las capacidades del Estado, refuerzo del Estado de Derecho y del respeto de los derechos humanos, fomento de la cooperación regional y prevención y represión del terrorismo ${ }^{92}$. Estrictamente en el terreno de la prevención, la PEV renovada está sirviendo para impulsar diálogos políticos en materia de seguridad y terrorismo con los países del Mediterráneo sur y, a la espera de que se negocien nuevos planes de acción específicos, los previstos anteriormente ya incorporaban aspectos a mejorar en el sector de la seguridad y la gestión de fronteras, financiados principalmente con cargo a la PCD y la PEV. Además, la UE ha incluido en la agenda bilateral el empoderamiento de la sociedad civil y el diálogo interreligioso e intercultural, apoyándose en la Fundación Anna Lindh ${ }^{93}$ y la financiación del

provocar inestabilidad e incrementar la vulnerabilidad ante la radicalización». ALTA REPRESENTANTE y COMISIÓN EuROPEA, «Comunicación conjunta al Parlamento Europeo, al Consejo, al Comité Económico y Social Europeo y al Comité de las Regiones. Revisión de la Política Europea de Vecindad», JOIN (2015) 50 final, Bruselas, de 18 de noviembre de 2015, p. 4.

${ }^{89} \mathrm{La}$ UE ha adoptado varias medidas para luchar contra el terrorismo específicamente en esta región subsahariana, entre las cuales es necesario destacar la Estrategia de la Unión Europea para la Seguridad y el Desarrollo en el Sahel, de septiembre de 2011 y el Plan de Acción para el Sahel (2015-2020), 7823/15, de 20 de abril de 2015. Además, el 16 de julio de 2012, el Consejo dio el visto bueno al despliegue de una misión civil de la PCSD en el Sahel para apoyar a las autoridades locales en la lucha contra el terrorismo y el crimen organizado transnacional. Para una perspectiva general del tema, véanse: BELLO, O., «La implementación de la estrategia de la UE para el Sahel: entre arenas movedizas», FRIDE Documento de Trabajo, 2012, núm. 114, disponible en: www.fride.org; EchEverRía, C., "Risks and Threats in the Western Sahel. Radicalization and Terrorism in the Sub-Region», Revue Paix et Sécurité Internationales, 2015, núm. 3, pp. 167-183; RouPPERT, B., «La Stratégie de l’UE pour le développement et la sécurité au Sahel 2011-2013 : Des efforts continus à pérenniser», Note d'Analyse du GRIP, de 17 de abril 2014, disponible en: http://www.grip.org/fr/node/1268.

90 «Las revueltas han generado como fruto inmediato la debilidad de algunos Estados que hasta el momento no habían tenido problemas para ejercer su soberanía sobre el territorio nacional. Este nuevo contexto de fragilidad institucional e incertidumbre política constituye por definición uno de los entornos donde el terrorismo puede regenerarse y desenvolverse con mayor facilidad». TORRES SORIANO, M., «El terrorismo yihadista tras las revueltas en el mundo árabe: menos agravios y nuevas oportunidades», Documentos de Opinión del Instituto Español de Estudios Estratégicos, 2013, núm. 13, p. 7.

91 Asamblea General, «Plan de Acción para Prevenir el Extremismo Violento. Informe del Secretario General», A/70/674, de 24 de diciembre de 2015.

92 Véase Gaub, F. y Pauwels, A., Counter-terrorism cooperation with the Southern Neighbourhood, Estudio solicitado por el Parlamento Europeo, Bruselas, 2017.

93 Cofinanciada por los 42 países miembros de la Unión por el Mediterráneo y la Comisión Europea, es una institución intergubernamental que aglutina a los actores de la sociedad civil y la ciudadanía en la región mediterránea con el fin de fomentar la confianza mutua y mejorar el entendimiento intercultural desde los ámbitos cultural, educativo y de los medios de comunicación de masas. Más información en: http://www.annalindhfoundation.org/. 
Instrumento Europeo de Vecindad de la $\mathrm{PEV}^{94}$, con el fin de impulsar una contrarréplica que evite la propagación de la propaganda radical terrorista especialmente entre la población joven de la región y promover su formación en materia de empleo, capacidades y liderazgo.

23. Es de destacar, sin embargo, que este impulso político y programático ha conocido escasos éxitos más allá de ser uno de los principales financiadores e impulsores de las normas de la ONU en terceros países. De hecho, sigue vigente en la actualidad parte de la perplejidad mostrada por Daniel Keohane hace casi una década sobre la ausencia de las medidas antiterroristas en el marco de la política exterior, parcialmente debido a una "complejidad institucional ${ }^{95}$ que el Tratado de Lisboa no ha llegado a resolver. Aparte de problemas intrínsecos, derivados principalmente del caos institucional y la debilidad de los instrumentos adoptados por la UE (diálogos políticos), circunstancias internas a los Estados del Sur del Mediterráneo han relegado a un segundo plano las propuestas europeas contra la radicalización terrorista ${ }^{96}$. No obstante, existen ciertos resquicios para la esperanza. En los últimos años estos esfuerzos han posibilitado que la UE haya introducido la prevención de la radicalización terrorista en sus relaciones con Estados terceros a través de la Ampliación y —en menor medida- la PEV, lo que conlleva la monitorización de las reformas e iniciativas de estos Estados terceros, con el soporte de la RSR y en colaboración con el Servicio Europeo de Acción Exterior y sus expertos contra el terrorismo desplegados en las delegaciones de la UE en el vecindario. Además, para bien o para mal, la prevención de la radicalización terrorista es uno de los pilares fundamentales de la PCD, de más amplio alcance geográfico y temporal, imprescindible para que la prevención del terrorismo y la radicalización surtan efectos y puedan cosechar éxitos a medio y largo plazo.

\section{CONCLUSIONES}

24. La prevención de la radicalización es una tarea difícil que requiere una respuesta multidimensional que la UE tiene complejo, por su propia estructura, poder desarrollar con plenitud. Moviéndose entre el soft law, la capacitación y las medidas represivas, la UE encuentra dificultades para abordar eficazmente el fenómeno de la radicalización terrorista, especialmente si tenemos en cuenta la complejidad misma de medir el éxito o fracaso de las medidas en este terreno. La radicalización es un proceso complejo, en el que intervienen factores sociales e individuales, y que requiere de una respuesta amplia y coordinada desde, entre otros ámbitos, los sectores del orden pú-

94 Este Instrumento, que financia la PEV en su totalidad, dispone de una línea específica de financiación de proyectos para el empoderamiento de la sociedad civil del sur del Mediterráneo, la Civil Society Facility South. Más información en: http://csfsouth.org/.

${ }_{95}$ Keohane, D., op. cit., nota 16.

96 Gaub, F. y Pauwels, A., op. cit., nota 92. 
blico y la seguridad, la educación y los servicios sociales. La respuesta de la UE es relativamente reciente, tímida y sesgada, pues no se ha tomado verdaderamente en serio su papel ni ha optado por un enfoque multidimensional hasta la revisión estratégica de 2014. No obstante, afirmar rotundamente que la prevención de la radicalización es un fracaso, simplemente porque dé la impresión de que no se haya conseguido acomodar en la sociedad europea a segundas generaciones de inmigrantes musulmanes, sería olvidar todos los avances en esta y otras materias de la prevención del terrorismo que se han sucedido en los últimos años, especialmente en aquellos sectores en los que la UE se siente más "cómoda» por tener competencia compartida: la intervención desde los ámbitos policial y de la justicia penal.

25. Dicho esto, es cierto que la UE se enfrenta a numerosos desafíos en la reestructuración de su intervención en un futuro inmediato si quiere lograr los objetivos marcados. En primer lugar, los propios límites del concepto, que no tiene respaldo unánime por parte de los EEMM y todavía hoy suscita indefiniciones y críticas por su excesiva ambigüedad. Asimismo, la UE ha de responder o, al menos, abordar el difícil equilibrio entre libertad y seguridad con el fin de evitar que derechos fundamentales básicos, como la libertad de asociación y expresión, no se vean menoscabados por unas medidas que, si ya en el seno de la UE claman la atención por desproporcionadas ${ }^{97}$, lo hacen aún más en determinados Estados terceros en los que estos derechos no son respetados ni existen garantías de protección frente a potenciales abusos de regímenes totalitarios. Ante posibles derivas, como han demostrado los recientes acontecimientos en Turquía, la Unión tiene que ser más cuidadosa en escoger los Estados terceros con los que coopera, al igual que en su discurso, evitando simplismos, si no quiere caer en las trampas de la propaganda radical que persigue eliminar. Ello precisaría de un mayor impulso de la participación de la sociedad civil y las diferentes comunidades religiosas para evitar ligar la prevención de la radicalización al Islam y combatir efectivamente la islamofobia. Por otra parte, es necesario replantearse el verdadero enfoque y alcance de las medidas para la prevención de la radicalización, tanto dentro como fuera de la UE. Las medidas previstas por la UE, a excepción de las impulsadas desde los ámbitos policial y judicial penal, se muestran insuficientes y no cumplen sus propósitos

97 En sus Conclusiones de abril de 2010, el Consejo propuso la creación de un «instrumento estandarizado, multidimensional y semiestructurado» para almacenar, procesar, interpretar y facilitar el intercambio de información entre las agencias, instituciones y EEMM. Este «instrumento» constaría de una serie de apartados sobre el tipo de ideología que apoya las manifestaciones violentas, descripción de los mensajes, vías de difusión de tales ideologías y mensajes, factores personales de los individuos involucrados (edad, sexo, nacionalidad, situaciones administrativa, económica y académica, antecedentes penales), entre otras muchas variables a cumplimentar por las autoridades competentes. Para ver el Anexo en el que se detalla este «instrumento», puede consultarse: $h t t p: / / w w w$. statewatch.org/news/2010/apr/eu-council-rad-instrument-7984-add1-10.pdf. Tanto Fernando Reinares como Rik Coolsaet cuestionan la utilidad para la prevención de la radicalización de este tipo de perfiles, pues no todos los individuos radicalizados o en riesgo responden a los elementos incorporados en estos listados, excesivamente simplistas. CoolsaEt, R., op. cit., nota 7, p. ¿¿???; ReINARES, F., op. cit., nota 7, p. 12 . 
si atendemos al auge de los delitos de incitación al odio y la proliferación de mensajes radicalizados en internet, por lo que una respuesta más contundente es necesaria. Asimismo, dicha respuesta ha de ser verdaderamente global, abordando la radicalización desde un enfoque multinivel -en el que se incorpore finalmente a los entes locales-, y multidimensional, en todos sus aspectos, no solamente aquellos relacionados con el terrorismo y la seguridad como hasta ahora.

26. Por último, es de lamentar que la acción exterior en materia de prevención del terrorismo y de la radicalización violenta siga compartida entre dos ámbitos de integración diferenciados: el ELSJ y la PESC/PCSD. A día de hoy, a pesar de algunos avances en materia de cooperación e intercambio de información entre Eurojust y Europol con las misiones y operaciones de la PCSD, la compartimentación de la acción exterior contra el terrorismo es todavía uno de los mayores problemas a los que se enfrenta la UE para garantizar su coherencia fuera de nuestras fronteras. Aunque la dimensión exterior del ELSJ pueda ejercer un positivo impacto en la lucha contra el terrorismo, la UE todavía no es capaz de ejercer influencia sobre terceros Estados para que estos adopten medidas eficaces contra la radicalización terrorista, en parte por la debilidad de los instrumentos de su acción exterior en aquellos casos en los que las autoridades locales no están interesadas en cooperar o están absorbidas por otras prioridades más inmediatas. Si la UE quiere ser un actor internacional y prevenir eficazmente la radicalización que conduce al terrorismo en su vecindario, además de corregir su discurso para hacer valer los beneficios de la colaboración antes sus interlocutores, tiene que poner fin a la artificial separación entre las dimensiones internas y externas de la seguridad, reforzar los instrumentos de su acción exterior contra el terrorismo y mejorar la coordinación de las diferentes políticas que inciden en la respuesta europea ante la radicalización terrorista.

\section{RESUMEN}

\section{LA PREVENCIÓN DE LA RADICALIZACIÓN EN LA ESTRATEGIA CONTRA EL TERRORISMO DE LA UNIÓN EUROPEA. ENTRE SOFT LAW E IMPULSO DE MEDIDAS DE APOYO}

En la última década, la Unión Europea (UE) ha prestado especial atención a las medidas de prevención del terrorismo y, en particular, de la radicalización terrorista, aportando una estrategia específica e instrumentos de apoyo que completan los esfuerzos de las autoridades nacionales en este ámbito de la seguridad. Sin embargo, debido a la complejidad del fenómeno y del propio reparto competencial, la respuesta multidimensional prevista por la UE adolece de deficiencias que reducen todo su potencial, dando la sensación de que ha fracasado en la consecución de sus objetivos si solamente nos atenemos a los actos terroristas acaecidos durante el último año en territorio europeo.

Palabras clave: radicalización, terrorismo, políticas de prevención, Unión Europea, Espacio de Libertad, Seguridad y Justicia. 


\section{ABSTRACT \\ THE PREVENTION OF RADICALIZATION IN THE EUROPEAN UNION'S COUNTER-TERRORISM STRATEGY. BETWEEN SOFT LAW AND THE PROMOTION OF SUPPORTING MEASURES}

During the last decade, the European Union (EU) has paid special attention to measures to prevent terrorism and, in particular, terrorism radicalization. It has developed a specific strategy and supporting instruments that complement Member States' efforts in this particular field of security. However, due to the complexity of the phenomenon and the distribution of the competences between the EU and its Member States, the multidimensional response envisaged by the EU manifests shortcomings that reduce its full potential, giving the impression that it has failed in fulfilling its main goals if one only takes into account the terrorist acts of the last year in Europe.

Keywords: radicalization, terrorism, prevention policies, European Union, Area of Freedom, Security and Justice. 